\title{
Special Issues on Learning Strategies: Parallels and Contrasts between Australian and Chinese Tertiary Education
}

\author{
Yuzuo Yao ${ }^{1}$ \\ ${ }^{1}$ School of Law, Central China Normal University, Wuhan, China \\ Correspondence: Yuzuo Yao, School of Law, Central China Normal University, 430079 Wuhan, China. E-mail: \\ yuzuoyao@mail.ccnu.edu.cn; yuzuoyao_ccnu@163.com
}

\author{
Received: July 13, $2017 \quad$ Accepted: August 20, $2017 \quad$ Online Published: November 28, 2017 \\ doi:10.5539/ies.v10n12p61 URL: https://doi.org/10.5539/ies.v10n12p61
}

\begin{abstract}
Learning strategies are crucial to student learning in higher education. In this paper, there are comparisons of student engagement, feedback mechanism and workload arrangements at some typical universities in Australia and China, which are followed by practical suggestions for active learning. First, an inclusive class would allow learners from different backgrounds to become more engaged in classroom activities. Second, universities should improve feedback mechanisms, making them more timely and helpful to enable students to adapt their learning strategies and allowing teachers to adjust teaching methods to target students effectively. Third, this paper proposes a framework of principles under which the flexible workload of academics should be ensured so that students can learn social skills from administrative staff and have more free time to develop unique thinking and planning capacities.
\end{abstract}

Keywords: tertiary education, learning strategy, student engagement, feedback mechanism, flexible workload

'The authority of whose who teach is often an obstacle to those who want to learn.'

Marcus Tullius Cicero

'Every word that is unnecessary only pours over the side of a brimming mind.'

Marcus Tullius Cicero

\section{Introduction}

As tertiary education has become increasingly international, several Chinese universities are prone to accept and enroll overseas students, while more and more Chinese students choose to study abroad. Since 1996, Chinese universities have cooperated with foreign countries to provide the degree-conferring programs (Huang, 2008, p. 29). According to the statistics provided by Australian Department of Education, Chinese students were the biggest single group of international students as a whole in 2011 and 2012 (Wang, Andre \& Greenwood, 2015, p. 609). Due to this tendency, the realm of the comparison of tertiary education is one focus of advanced pedagogy. With a better understanding of learning strategies in higher education, from a comparative level in practice, new insights into the issues supporting learning strategies could be of importance, contributing to the evolution and innovation of universities in Australia, China and others.

The content of learning strategies has been provided by many scholars pioneering much of the work in the field of education. Schmeck (1988) defines learning strategy broadly as 'a sequence of procedures for accomplishing learning' (p. 5). Rubin has indicated the indirect steps or techniques that facilitate learning, includes creating practice opportunities and using production tricks, such as communication strategies (O'Malley \& Chamot, 1990, p. 3). In China, modern researchers have stated that learning strategies consist of four layers: cognitive strategies, meta-cognitive strategies, motive strategies and management strategies (Zhao, Yang, \& Shi, 2005, p. 79). Arguably, learning strategies are not only core approaches used in teaching, but also other special mechanisms that support the learning process of students, whether they contribute to learning directly or indirectly. With a purpose to improve students' motives, time management strategies, communication skills and so on, these special issues that could potentially influence learning outcomes and satisfaction of students should be integrated into a tertiary education system.

There is a need for more critical and comparative analysis so that the dynamics behind the learning process can 
be found and the quality of students' learning so enhanced. This paper is the result of an international research which has been completed in Australia and China. Comparison is only a starting point to provide an overview and detailed cases of what is happening to Australian and Chinese universities. Further analysis will then go beyond description into the dynamics behind the learning process. At the core of this paper, Section 2, Section 3 and Section 4 examine similarities and differences across the cases of learning strategy components, including student engagement, timely and effective feedback and flexible workload at some typical universities in Australia and China respectively, and each component analysis will be followed by suggestions or a proposed framework at the end. Finally, the author draws several conclusions.

\section{Student Engagement}

Much attention has been paid in both Australia and China to the engagement of students, but this might become more challenging for China than Australia. Both of them realize that active learning approaches can work well in promoting students engagement with lecturers. For example, the flipped class approach has been adopted in these two countries and has turned traditional learning on its head by engaging students and shifting their passive recipients' role to active constructors.

Nevertheless, implementing an approach of active learning seems to be more difficult in China than in Australia being that the number Chinese students enrolled in one class may be very high. According to a recent survey of student engagement at 6 Chinese universities spread out across 4 cities, engaging students accounts for one third of all the students under investigation (Gao, 2015, p. 5).

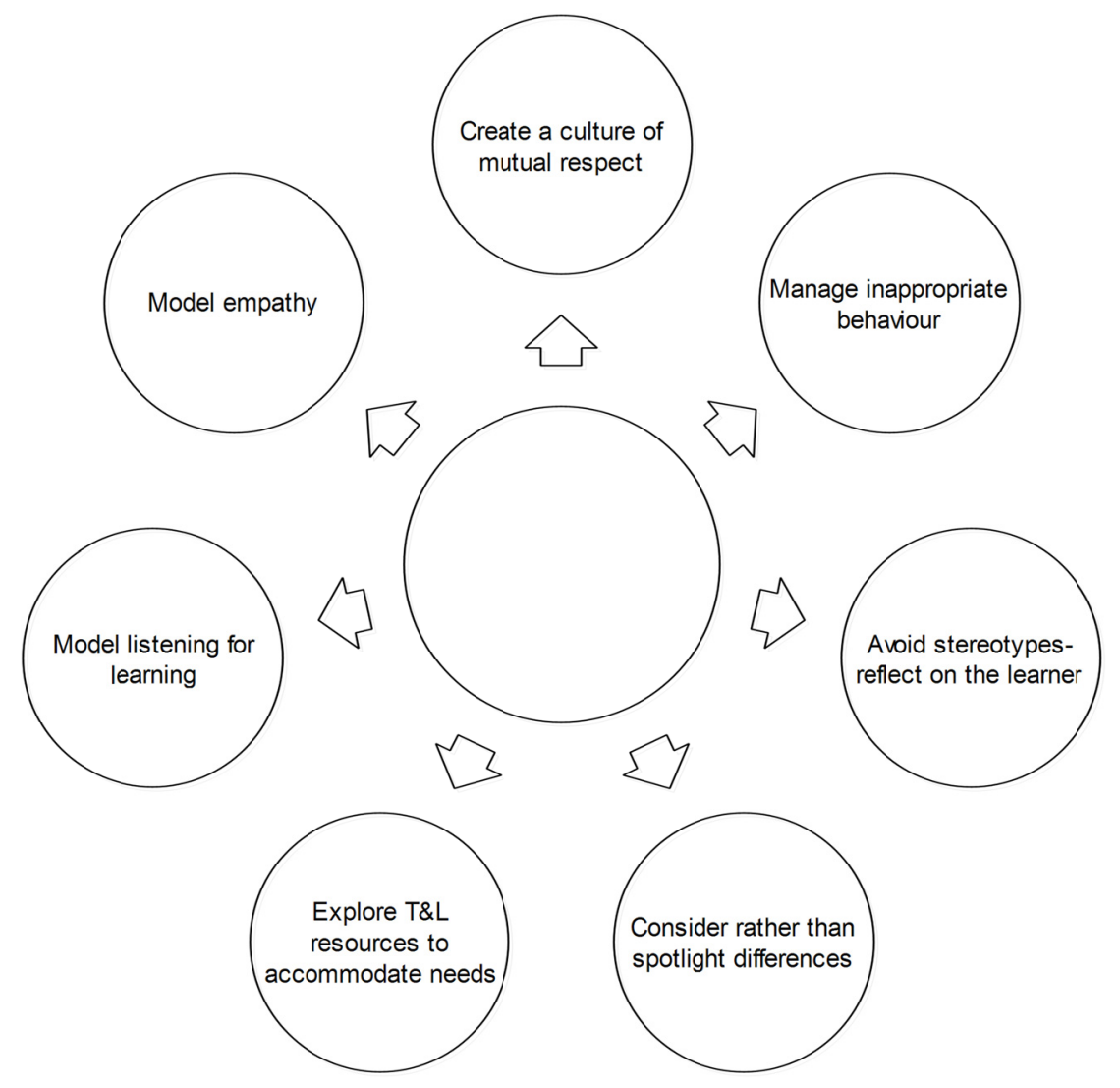

Figure 1. Creating an inclusive teaching and learning environment

Note. From 'Inclusive Teaching Practices' by Deakin University (p. 2)

At the same time, there are open-mind, unbiased and inclusive learning strategies that are capable of motivating diverse students. At many Australian universities, students come from different backgrounds, probably equipped with different skills, learning styles and values associated with traditional cultures. For instance, Macquarie University allows students from different nations or countries to introduce their various cultures and fields of knowledge with the objective of improving a sense of belonging to their class or to reduce alienation (Learning 
and Teaching Center for Macquarie University, 2009, p. 1). Moreover, Deakin University has contrived a strategy to create an inclusive teaching and learning environment, with 'a view of the individual and individual difference as the source of diversity that can enrich the lives and learning of others' (Deakin University, n.d., p. 1). As shown in Figure 1, the items related to the design of an inclusive teaching and learning environment include creating a culture of mutual respect, modeling empathy, modeling listening for learning, exploring teaching and learning resources to accommodate needs, considering rather than spotlighting differences, avoiding stereotypes-reflect on the learner and managing inappropriate behaviour (Deakin University, n.d., p. 2).

Likewise, inclusive learning strategy can support student engagement in China. Not only does China have a large population of students who come from different families widely distributed across many provinces in a multi-ethnic and multicultural country, but, to achieve strategic goals of internationalization, several Chinese universities are also prone to accept and enroll overseas students. For instance, Shandong University enrolls more international students for study or internship, and co-supervises students together with overseas professors (Wang, 2009, p. 63). The students may possess a range of abilities and have various educational needs. These courses are then intended to be designed or delivered in an inclusive way, otherwise the students might become anxious, disengaged or even reluctant learners in class.

There is concern as to whether such barriers to inclusive education to a large number of students can be removed or reduced. In order to create an inclusive educational environment, this paper discusses three crucial points in regard to student engagement. Firstly, the students should be permitted to introduce their special background to the class, and then teachers will be enabled to identify the motivating topics and special experiences that students bring to the course. Biggs (1996) indicates 'the learner brings an accumulation of assumptions, motives, intentions, and previous knowledge that envelopes every teaching/learning situation and determines the course and quality of the learning that may take place' (p. 348).

Secondly, in designing curricula, teachers will realize that every student is able, or at least has an opportunity, to be understood and develop in class. The teachers will therefore still need to set the objectives for learning as before. More precisely, however, this will not involve a process of design but more a process of discovery, which frames the learning process as a dynamic conversation rather than a frozen snapshot of knowledge. The courses can be delivered in a discoverable and flexible way, thus allowing interaction between different students, as well as between students and academics.

Thirdly, students will reach a higher level of participation if they are better involved in a stream in collaboration with others. There is common consensus among Chinese teachers that students can be more engaged if large classes are divided into smaller groups. Teachers can then give useful information as well as instructions, while not privileging any one group of students or disadvantaging other groups of students. Students will therefore be able to interact with each other and so reach an agreement or an equilibrium that is very likely aligned with their learning objectives.

\section{Feedback Mechanism}

'Learning strategies are kind of implicit learning skills. Appropriate teaching methods play an important role in students' acquisition and application of learning strategies' (Li \& Xue, 2008, p. 229). There is a need for an effective feedback mechanism, according to which students are able to reflect on their work and adapt and adjust their learning strategies. In addition, teachers are obliged to improve their teaching methods to help students develop implicit skills to accomplish specific learning tasks.

There are both parallels and contrasts between Australia and China in terms of feedback mechanism.

In Australia, universities usually adopt an appropriate system to provide effective feedback to students, as well as to teachers, in order to enhance the effectiveness of learning. Feedback to students is designed to improve reflections on the students' part. Teachers' feedback to students must be timely so as to assist them in developing their essential understanding, strategies and skills. At Macquarie University, this concerns not only teachers' review but also students' peer review; in particular when a group discussion is run, promoting reflection by students on their studies (Learning and Teaching Center for Macquarie University, 2009, p. 2).

It is possible for teachers at Australian universities to receive feedback from both students and other academics. The routine use of students' feedback to teachers contributes to recognizing and meeting the various needs of students in class. After collecting different students' feedback, teachers are supposed to accommodate diversity in learning strategies and to work on the problems in their teaching approaches. Alongside student feedback is an academic peer review that is adopted at many Australian universities. 'Students have long been the primary arbiters of teaching, but they have not provided either the breadth or depth necessary to evaluate the broader 
spectrum of teaching effectiveness' (Malik, 1996. p. 277). In a peer review, by contrast, 'a colleague is not only able to observe the teacher and what he or she may be doing, but they are in the unusual position of being able to observe the students and their level of engagement, interest and participation' (Farrell, 2011, p. 6). An example of a peer review from Melbourne University can be seen in Table 1, there are two sections in the peer review. Section 1 is a report of teaching observation and Section 2 is a response form (Farrell, 2011, p. 23). These forms can be used to justify promotion or for teaching awards, but this information taken from peers should be triangulated with other sources (Farrell, 2011, p. 13).

Table 1. Report and response-teaching observation at Melbourne University

Section 1 - Report
This section is completed by the reviewer, drawing upon Form B (Feedback framework) and any notes made during the teaching
session. Please use as much space as required.
1. Demonstrating enthusiasm \& stimulating curiosity
2. Encouraging critical thinking and student learning
3. Features of effective communication
4. Session mechanics
5. Priority criteria (as discussed by reviewee and reviewer)
6. Are there any examples of good practice you would particularly like to highlight?
Section 2 - Response (optional)
The reviewee has the option to complete this section following the feedback meeting with the reviewer.
These notes may be of assistance in completing future probation, performance appraisal and/or promotion application processes.
Please respond to the feedback provided. You may like to address aspects of the feedback that you might incorporate into your
teaching in future, as well as discussing any feedback where you may differ in opinion from your reviewer.

Note. From 'Collegial Feedback on Teaching: A Guide to Peer Review' by Farrell (2011, p. 23)

Currently, a number of Chinese universities have adopted or experienced the same feedback systems as those in Australia, although with a difference in the details. Take Central China Normal University (CCNU), for example. $\mathrm{CCNU}$ is a typical university, being best known for its educational excellence in training teachers in China. With regard to the feedback to students, the teachers generally manage to interact and give their feedback to students in time. Moreover, it has been proposed that students should obtain more feedback from their students' group members if they are involved in teamwork.

Table 2. Teaching observation at Central China Normal University

\begin{tabular}{|c|c|c|c|c|c|}
\hline & Assessment Items & A & B & C & D \\
\hline 1 & Demonstrating enthusiasm \& holding students' attention & & & & \\
\hline 2 & Familiar with the curriculum \& good at expression & & & & \\
\hline 3 & Making the course simple, clear and stimulating students \& emphasizing the key points & & & & \\
\hline 4 & Containing an appropriate amount of information & & & & \\
\hline 5 & Relating to new ideas, new concepts and new contribution in the discipline & & & & \\
\hline 6 & $\begin{array}{l}\text { Encouraging critical thinking, stimulating curiosity and developing students' } \\
\text { associative ability }\end{array}$ & & & & \\
\hline 7 & Effective communication and lovely atmosphere in class & & & & \\
\hline 8 & Making the best of various teaching media & & & & \\
\hline 9 & Establishing order in class & & & & \\
\hline 10 & Dressing in a dignified manner \& complying with the regulation of teachers & & & & \\
\hline \multicolumn{6}{|c|}{ Other comments or suggestions: } \\
\hline
\end{tabular}

Note. From ‘Hua Zhong Shi Fan Da Xue Gan Bu, Jiao Shi Ting Ke Zhi Du’ by Central China Normal University, 2015 
With respect to the feedback to teachers, teachers usually receive the final feedback from students as arranged by the university at the end of a semester and the peer review mechanisms are arranged by faculties. In practice, many teachers try to capture students' response in the middle of a semester, but as a result of the lack of formal channels, some students with learning problems fail to achieve their highest possible level. It would be better if compulsory students' feedback to teachers were arranged in time so that the teachers could shift to new teaching methods to help the target students during the learning process.

The peer review of teaching has been adopted at many Chinese universities. For example, it has been implemented at CCNU over a period of more than ten years (Central China Normal University [CCNU], 2005). As shown in Table 2, the information acquired covers many issues in relation to teaching and learning in class, including the effectiveness of learning activities, teaching methods and even teachers' dress. As a topic, the peer review of teaching is quick to raise hackles and arouse fears, especially among faculty (Hutchings, 1996, p. 224), but that would be a change at CCNU. The peer feedback cannot be taken into account for the evaluation of teachers' performance. The peer review of teaching can, in its most powerful forms, be less a matter of judging teachers than of improving teaching, with the focus moving increasingly to ways for them to help each other improve the quality of collective contribution to students' learning (Hutchings, 1996, p. 233).

\section{Flexible Workload}

As the implementation of learning strategies requires significant time input from teachers, both Australian teachers and Chinese teachers are now devoting much of their spare time, either in-class or out-of-class, to students' ongoing learning activities. Underpinning this reform is the idea that the greater the workload academic teachers carry, the more effective learning will be achieved.

On the contrary, not only are a number of academics take on heavy workloads, but also student workloads are also increasing unwittingly. If the staff gets too involved with students, the latter may not be able to spend their free time in developing unique thinking and planning capacities in this process. It seems that although teachers need to devote more time in consistency with educational objectives set by universities, but these objectives cannot be or would not be appropriately pursued in these circumstances.

The apparent failure of current implementation of learning strategies is partly due to following reasons. One primary reason is related to the increasing working pressure of academics. In Figure 2, Chinese student numbers had increased by over seven times, to almost 7 million new students, 25 million students in total, and 6.4 million graduates by 2013 (Soo, 2015, p. 639). As with China, 'the student-staff ratio in Australian universities has risen steadily since 1994 with no sign of slowing and with the added pressure of increasing numbers of overseas students. This places additional, sometimes unmanageable, pressures on staff' (Hammond \& Churchman, 2008, p. 238).

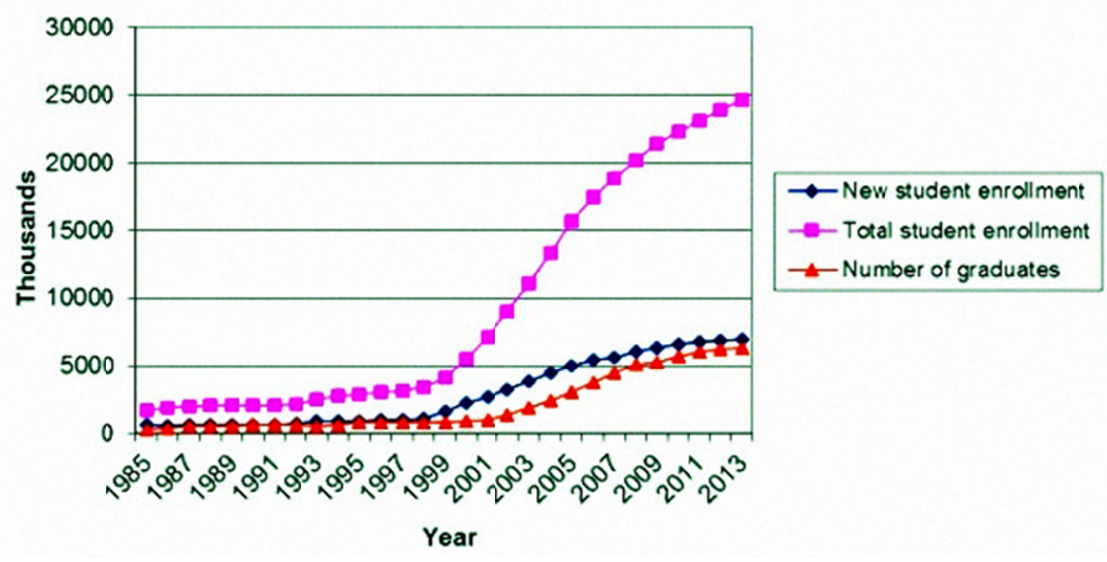

Figure 2. Student numbers in regular institutions of higher education in China, 1985-2013

Note. From 'Recent Trends in Graduate Unemployment and Higher Education in China' (Soo, 2015)

The total working hours were significantly long in both Australia and China. As shown Table 3, at Australian universities and Chinese universities, full-time staff work 49.2 hours and 49.9 hours per week respectively 
(Bentley \& Kyvik, 2011, p. 535). The total working hours was also observed by other researchers and in comparison, they indicate that Australian academics, both in junior and senior ranks, work 43.8 and 50.4 hours per week respectively (Kenny, Fluck, \& Jetson, 2012, p. 51).

Table 3. Mean weekly hours on academic activities when classes are in session, by country and region

\begin{tabular}{lccccccc}
\hline Country/region & Teaching & Research & Admin. & Service & Other & Total & $\mathrm{N}$ \\
\hline English-speaking & $20.4^{*}$ & $14.3^{*}$ & $9.1^{*}$ & $3.2^{*}$ & $3.2^{*}$ & $50.1^{*}$ & 2.484 \\
Australia & 19.7 & $13.7^{*}$ & $9.7^{*}$ & $3.0^{*}$ & 3.0 & $49.2^{*}$ & 526 \\
Canada & 21.0 & $16.1^{*}$ & $7.7^{*}$ & $3.5^{*}$ & 2.9 & $51.1^{*}$ & 702 \\
UK & 20.0 & $12.6^{*}$ & $11.1^{*}$ & $1.4^{*}$ & 3.6 & $48.8^{*}$ & 569 \\
USA & 20.7 & 14.6 & $8.0^{*}$ & $5.0^{*}$ & 3.1 & $51.4^{*}$ & 687 \\
Western Europe & $20.1^{*}$ & $16.3^{*}$ & $5.7^{*}$ & 3.3 & $2.9^{*}$ & $48.3^{*}$ & 2.729 \\
Finland & $23.4^{*}$ & $12.6^{*}$ & $6.0^{*}$ & $2.6^{*}$ & 2.6 & $47.2^{*}$ & 393 \\
Germany & $15.5^{*}$ & $20.1^{*}$ & $5.0^{*}$ & $6.1^{*}$ & $3.4^{*}$ & $50.2^{*}$ & 612 \\
Italy & $19.4^{*}$ & $18.1^{*}$ & $4.5^{*}$ & $2.5^{*}$ & $2.4^{*}$ & $46.9^{*}$ & 1.358 \\
Norway & $22.0^{*}$ & $14.3^{*}$ & $7.3^{*}$ & $2.1^{*}$ & $3.3^{*}$ & 48.9 & 366 \\
Asia & $20.7^{*}$ & $14.9^{*}$ & $7.8^{*}$ & $3.4^{*}$ & 3.0 & $49.7^{*}$ & 1.272 \\
China & 20.6 & $18.8^{*}$ & $5.4^{*}$ & 2.9 & $2.2^{*}$ & $49.9^{*}$ & 429 \\
Hong Kong & 21.7 & $15.9^{*}$ & $8.3^{*}$ & 3.6 & $3.4^{*}$ & $52.8^{*}$ & 527 \\
Malaysia & 19.7 & $10.0^{*}$ & $9.7^{*}$ & 3.7 & $3.3^{*}$ & $46.3^{*}$ & 316 \\
Latin America & $17.2^{*}$ & $17.5^{*}$ & $5.4^{*}$ & $2.7^{*}$ & $2.6^{*}$ & $45.4^{*}$ & 632 \\
Argentina & $14.8^{*}$ & $20.7^{*}$ & 4.6 & 2.9 & 2.2 & 45.2 & 371 \\
Brazil & $19.6^{*}$ & $14.4^{*}$ & 6.3 & 2.5 & 3.0 & 45.7 & 261 \\
All countries & 19.6 & 15.7 & 7.0 & 3.2 & 2.9 & 48.4 & 7.117 \\
\hline
\end{tabular}

* ANONA significant difference in means between given country and at least one other country within the same region, or significant difference between given region and at least one other region. $p<0.05$

Note. From 'Academic Work from a Comparative Perspective: A Survey of Faculty Working Time across 13 Countries' Bentley and Kyvik (2011)

'Their increasing workload has resulted in a situation where they can simply not afford to take up flexible work arrangements' (Sharafizad, Paull, \& Omari, 2011, p. 46). 'Flexible' is commonly viewed as 'non-standard' (Gardiner \& Tomlinson, 2009, p. 672). Flexible work arrangements can be defined as 'any policies, practices, formal or informal, which permit people to vary when and where work is carried out' (Maxwell, Rankine, Bell, \& MacVicar, 2007, p. 138). In the past, academic careers were traditionally able to take advantage of flexible work, but this attractiveness has not been able to continue since their working hours on campus are going up. On the contrary, these academics should not be bound to the campus or a specific office. They need time to prepare the courses, conduct research, prepare for conference and broaden their knowledge, even when they are at home or on leave which may not be correctly recognized by the existing workload model at universities.

Confusing roles between the academics and the general administrative staff is the other cause. In fact, academics have been allocated to engage with much work with students' communities in China and are supposed to complete many reports and tasks concerning administrative work. The further evidence in the study of Australian universities shows that administrative staff and academic staff 'have somewhat negative perceptions about each other's workloads' (Sharafizad, Paull, \& Omari, 2011, p. 47).

There is thus as absence of proper principles and guidelines for the allocation of workload result in ineffective learning strategies. It is suggested that universities should set up an appropriate framework with key principles, under which appropriate or flexible time could be ensured.

Principle 1: Limiting the maximum working hours

Some universities have given much thought to the principle of limiting maximum working hours. For example, the University of South Australia (2014) states that over the course of a service year, the total of allocated activities for a full-time academic should not exceed 1725 hours (including 4 weeks of recreation leave) (p. 9).

More importantly, preparation of the courses should be taken into account. In particular, there is a need for a commensurate increase in calculating working time of the academics, particularly for a new teacher. The current model of many universities does not adequately consider the extra time involved in preparation for a new course. 
This would not fair to a new teacher or a teacher who has never taught the course concerned before.

Principle 2: Setting expectations for work and eliminating fragmentation of time

Flexibility will be improved tremendously if expectation of work is enhanced. For example, once academic teachers are required to submit their report with signature in person they will have to cease their research at hand and spend time on the journey to campus. When they return to their work in research, it may not be easy for them to pick up their research again. Furthermore, administrative staff often ask the academics to perform the endless work associated with administration, leaving their administrative work for academic colleagues to do. Many Australian and Chinese universities are trying to switch the offline administrative work to online work, which would be more convenient for staff in terms of submitting documents from home. In practice, universities should avoid the negative effect of the fragmentation of time in research by setting clear expectations for work.

Principle 3: Clarifying the role of administrative staff in students' communities

It would be better if the administrative staff could participate more in students' activities. Students societies or communities are at the heart of student life beyond the classroom. These activities run by students are different from the courses taught by academic staff, providing students with the opportunities to contact the staff and practice their communication skills, negotiation skills, leadership skills, and so on. While academic teachers are often invited or required to take part in various activities, administrative staffs are seldom involved in students' life. Even some administrative staff respondents indicate that few students know their names. Compared with the academic staff, the administrative staffs have strong organizational skills which overlap with those skills students want to acquire out of class. Thus, administrative staffs are supposed to become more proactive in students' communities, being that computers save their time. Hopefully, the workload will be spread evenly between academic staff and administrative staff in students' communities in the future.

\section{Conclusion}

Learning strategies are crucial in student learning in higher education. To embody an idea of active learning strategies in a whole procedure, the special issues that could support learning directly or indirectly need to be addressed. Although there are some similarities of learning strategies in both Australia and in China, they are not carried out at the same level.

Section 2 pointed out that China and Australia have paid much attention to student engagement, in particular their participation in inclusive classes, but this might become more challenging for China than for Australia partly because China has a large population of students. Students will demonstrate a greater participation if large classes are divided into smaller streams. When the learners from different parts of China or different countries bring their assumptions, motives, intentions and previous knowledge to the class, they will develop a sense of belonging within the classroom context. In designing a course, the teachers can discover dynamics instead of delivering knowledge, and allow interaction between different students.

Section 3 is concerned with improving the feedback mechanism in some Chinese universities which are somewhat different from Australian universities in details. With regard to feedback to students, students working in groups can obtain feedback from other group members. In terms of feedback to teachers, it would be better if students' feedback could be timely so that the teachers would adjust teaching methods to the target students immediately. Besides, universities shall improve the peer review of teaching by making it more helpful.

The workload of academic staff has been increasing, resulting in a situation where they cannot take up flexible work arrangements. In Section 4, there is a proposed framework of principles. First, universities should limit the maximum working hours and take into account the preparation of courses. Second, flexibility will be improved tremendously if research time is continuous, not fragmented, enhancing the expectation of their work. Third, administrative staffs are supposed to become more proactive in students' communities.

As a whole, insights into the issues supporting learning strategies are of considerable significance, particularly in Australia and China, and are also relevant to other countries. The proposals put forward in this article may be very applicable and therefore offer some ideas for further research in this field.

\section{Acknowledgments}

The author would like to acknowledge the help of staff at University of Macquarie, Zlata Kazic, Andrea Phillips, Dr. Panos Vlachopoulos and Dr. Gordon Joughin, whose courses and discussion on teaching greatly improved this paper. Also, special thanks go to Alexandra McPaul, a project manager of co-curricular at University of Wollongong, for meaningful and insightful conversations about tertiary education. 


\section{References}

Bentley, P. J., \& Kyvik, S. (2011). Academic Work from a Comparative Perspective: A Survey of Faculty Working Time across 13 Countries. Higher Education, 63(4), 529-547. https://doi.org/10.1007/s10734-011-9457-4

Biggs, J. (1996). Enhancing Teaching through Constructive Alignment. Higher Education, 32, $347-364$. https://doi.org/10.1007/BF00138871

Central China Normal University. (2005). Hua Zhong Shi Fan Da Xue Gan Bu, Jiao Shi Ting Ke Zhi Du. Retrieved from http://jwc.ccnu.edu.cn/showNews.aspx?id=228

Deakin University. (n.d.). Inclusive Teaching Practices. Retrieved from http://www.deakin.edu.au/__data/assets/pdf_file/0004/53482/inclusive-teaching.pdf

Farrell, K. (2011). Collegial Feedback on Teaching: A Guide to Peer Review. Retrieve from http://www.cshe.unimelb.edu.au/

Gao, H. (2015, July 8). Diao Cha Xian Shi: Da Xue Sheng Ke Tang Can Yu Du Ji Dai Ti Gao. China Education Daily (p. 5).

Gardiner, J., \& Tomlinson, J. (2009). Organizational Approaches to Flexible Working: Perspectives of Equality and Diversity Managers in the UK. Equal Opportunities International, 28(8), 671-686. https://doi.org/10.1108/02610150911001706

Hammond, C., \& Churchman, D. (2008). Sustaining Academic Life: A Case for Applying Principles of Social Sustainability to the Academic Profession. International Journal of Sustainability in Higher Education, 9(3), 235-245. https://doi.org/10.1108/14676370810885862

Huang, B. (2008). Regulation and Practice of Transnational Higher Education in China. In L. Dunn \& M. Wallace (Eds.), Teaching in Transnational Higher Education: Enhancing Learning for Offshore International Students (pp. 23-33). New York, NY: Routledge Taylor \& Francis Group.

Hutchings, P. (1996). The Peer Review of Teaching: Progress, Issues and Prospects. Innovative Higher Education, 20(4), 221-234. https://doi.org/10.1007/BF01185797

Kenny, J., Fluck, A., \& Jetson, T. (2012) Placing a Value on Academic Work: the Development and Implementation of a Time-Based Academic Workload Model. Australian Universities' Review, 54(2), 50-60.

Learning and Teaching Center for Macquarie University. (2009). Student Engagement Principles. Retrieved from http://staff.mq.edu.au/public/download.jsp?id=214696

Li, H., \& Xie, B. (2008). Jia Qiang Da Xue Sheng Xue Xi Ce Lue Yu Ti Gao Da Xue Sheng Zi Zhu Xue Xi Neng Li. Economic Research Guide, 37(18), 228-229.

Malik, D. J. (1996). Peer Review of Teaching: External Review of Course Content. Innovative Higher Education, 20(4), 277-286. https://doi.org/10.1007/BF01185803

Maxwell, G., Rankine, L., Bell, S., \& MacVicar, A. (2007) The Incidence and impact of Flexible Working Arrangements in Smaller Businesses. Employee Relations, 29(2), 138-161. https://doi.org/10.1108/01425450710719987

O’Malley, J. M., \& Chamot, A. U. (1990). Learning Strategies in Second Language Acquisition. Cambridge: Cambridge University Press.

Schmeck, R.R. (1988). An Introduction to Strategies and Learning Styles. In R. R. Schmeck (Ed.), Learning Strategies and Learning Styles (pp. 3-20). New York, NY: Pleum Press. https://doi.org/10.1007/978-1-4899-2118-5_1

Sharafizad, F., Paull, M., \& Omari, M. (2011). Flexible Work Arrangements: Accessibility in a University Environment. Australian Universities'Review, 53(2), 43-49. https://doi.org/10.1080/09585192.2011.540163

Soo, K. T. (2015). Recent Trends in Graduate Unemployment and Higher Education in China. Higher Contemporary Chinese Political Economy and Strategic Relations: An International Journal, 1(3), 637-661.

University of South Australia. (2014). Academic Workload Guidelines. Retrieved from $\mathrm{http} / / / \mathrm{w} 3 . u n i s a . e d u . a u / h r m /$ industrial/academic_workload_guidelines_FINAL.pdf 
Wang, C. C., Andre, K. \& Greenwood, K. M. (2015). Chinese Students Studying at Australian Universities with Specific Reference to Nursing Students: A Narrative Literature Review. Nurse Education Today, 35, 609-619.

Wang, J. (2009). The Internationalization of Higher Education in China: The Case of One University. In T. Coverdale-Jones, \& P. Rastall (Eds.), Internationalizing the University: The Chinese Context (pp. 57-71). Basingstoke: Palgrave Macmillan. https://doi.org/10.1016/j.nedt.2014.12.005

Zhao, J., Yang, Y., \& Shi, B. (2005). The Development of Undergraduates' Learning Strategies. Psychological Development and Education, 4, 79-81.

\section{Copyrights}

Copyright for this article is retained by the author(s), with first publication rights granted to the journal.

This is an open-access article distributed under the terms and conditions of the Creative Commons Attribution license (http://creativecommons.org/licenses/by/4.0/). 